\title{
Lipoproteins in pregnant women before and during delivery: influence on neonatal haemorheology
}

\author{
J Uberos-Fernández, A Muñoz-Hoyos, A Molina-Carballo, A Puertas-Prieto, \\ A Valenzuela-Ruiz, C Ruiz-Cosano, J A Molina-Font
}

\begin{abstract}
Aims-To investigate whether the lipid profile of pregnant women during parturition differs from the profile at previous stages of pregnancy and to determine the effects of maternal lipid changes on fetal or neonatal haemorheology.

Methods-Sixty pregnant women were studied, divided into two groups. Group 1 contained 30 women of mean age of 27 (SD 3) years and gestational age $>38$ weeks in whom delivery had not yet begun; all these pregnancies followed an uncomplicated course and there was no evidence of any fetal pathology from previous obstetric examinations. All the women reached term and birth weight was 3340 (350) g. Group 2 contained women of mean age 26 (4) years, in whom delivery was ongoing, all of whose pregnancies reached term. The following variables were determined in all cases: total cholesterol, triglycerides, high density lipoproteins (HDL), low density lipoproteins (LDL), free fatty acids and phospholipids, and apoprotein $A$ (apo-A) and apoprotein B (apo-B). Serum and plasma viscosity was measured with a capillary viscosimeter.
\end{abstract}

Results-The apo-B/apo-A and HDL/apo$A$ ratios increased during delivery, indicating that in pregnant women these atherogenic indices are raised during delivery compared with previous gestational stages. Significant correlation coefficients were obtained between maternal lipids (triglycerides, total cholesterol, LDL, total cholesterol/HDL, and LDL/HDL) and plasma viscosity in the neonate.

Conclusions-Plasma atherogenic indices increase progressively until birth. These changes have implications for neonatal haemorheology because they cause an increase in plasma viscosity.

(f Clin Pathol 1996;49:120-123)

Keywords: pregnancy, delivery, hyperlipidaemia, blood rheology, fetus, newborn.

Hormonal changes occurring during pregnancy induce changes in lipid composition, making it more atherogenic as pregnancy progresses. ${ }^{1-4}$ Increases in total cholesterol, triglycerides, and LDL cholesterol and decreases in HDL cholesterol and apolipoprotein A (apo-A) have been reported in uncomplicated pregnancies. ${ }^{45}$ In complicated pregnancies-for example, where there is retarded intrauterine growth, changes in the lipid profile have been described which do not occur in uncomplicated pregnancies. In such pregnancies there is a decrease in triglyceride and apo-A concentrations accompanied by increases in the apolipoprotein $B$ (apo-B) and in the apo-B/apo-A and HDL apo-A ratios. ${ }^{4}$ This increase in plasma atherogenicity explains the placental vascular changes responsible for fetal malnutrition in pregnant women with retarded intrauterine growth.

Few studies have been published on lipoprotein values in pregnant women during delivery. The stress experienced during delivery probably induces changes in the lipid profile compared to the reference values at previous gestational stages. Our main objective in this study was, firstly, to investigate whether the lipid profile during delivery differs from that at previous gestational stages, and secondly, to determine the effects of maternal lipid changes on fetal and neonatal haemorheology.

\section{Methods}

SAMPLE DEFINITION AND CHARACTERISTICS

Sixty pregnant women were divided into two homogeneous groups with respect to age. Group 1 contained 30 pregnant women with a mean age of 27 (SD 3) years and a gestational age between 38 and 42 weeks in whom delivery had not yet begun; all these pregnancies followed an uncomplicated course and there was no evidence of any fetal pathology from previous obstetric examinations. In patients of this group there was a period of more than a week between blood sampling and the onset of delivery. All these women reached term and the birth weight averaged 3340 (SD 350) g. Delivery was non-instrumental and all the neonates had an Apgar score of $>7$ at one minute. Group 2 contained 30 women aged 26 (4) years at delivery, all deliveries being at term. As in group 1, delivery was non-instrumental and there was no evidence of previous obstetric pathology. No mother was included in both groups.

\section{PROCEDURES}

The studies were approved by the ethics committee of the Virgen de las Nieves Hospital. Blood samples were taken from fasting women in group 1 for analytical tests. Samples were taken from group 2 women during delivery but before giving birth, with their previous 
Table 1 Protein, serum, and plasma viscosity in pregnant women and in umbilical cord blood. Values are means (SD)

\begin{tabular}{|c|c|c|c|c|c|}
\hline \multirow[b]{2}{*}{$\begin{array}{l}\text { Plasma viscosity }(\mathrm{mPa} / \mathrm{s}) \\
\text { Serum viscosity }(\mathrm{mPa} / \mathrm{s}) \\
\text { Albumin (g/litre) } \\
\alpha_{1} \text { Globulin (g/litre) } \\
\alpha_{2} \text { Globulin (g/litre) } \\
\beta \text { Globulin (g/litre) } \\
\gamma \text { Globulin (g/litre) }\end{array}$} & \multicolumn{2}{|c|}{ Pregnant women (38-42 weeks) } & \multicolumn{2}{|c|}{ Pregnant women (delivery) } & Newborn (umbilical vein) \\
\hline & $\begin{array}{cl}1 \cdot 1 & (0 \cdot 15) \\
0.95 & (0 \cdot 08) \\
35 & (3) \\
3 \cdot 2 & (0 \cdot 5) \\
6.9 & (1 \cdot 4) \\
10 & (1 \cdot 6) \\
7 & (1.5)\end{array}$ & $\begin{array}{l}\text { NS } \\
\text { NS } \\
\text { NS } \\
\text { NS } \\
\text { NS } \\
\text { NS } \\
\text { NS }\end{array}$ & $\begin{aligned} 1 \cdot 13 & (0.12) \\
0.98 & (0.08) \\
34 & (5 \cdot 4) \\
3 & (0.6) \\
6.5 & (1 \cdot 7) \\
10 \cdot 2 & (1.9) \\
6.9 & (2 \cdot 2)\end{aligned}$ & $\begin{array}{l}\ddagger \\
\ddagger \\
\ddagger \\
\ddagger \\
\ddagger \\
\ddagger \\
\ddagger\end{array}$ & $\begin{aligned} 1.02 & (0 \cdot 1) \\
0.94 & (0.07) \\
38 \cdot 7 & (4 \cdot 4) \\
1.9 & (0 \cdot 4) \\
4 \cdot 2 & (1 \cdot 0) \\
5.4 & (1 \cdot 5) \\
9.5 & (0.19)\end{aligned}$ \\
\hline
\end{tabular}

$\dagger \mathrm{p}<0.01 ; \ddagger \mathrm{p}<0.001$.

Table 2 Apolipoproteins and lipid lipoprotein ratios in pregnant women and in umbilical cord blood. Values are means $(S D)$

\begin{tabular}{|c|c|c|c|c|c|}
\hline \multirow[b]{2}{*}{$\begin{array}{l}\text { TG (mmol/litre) } \\
\text { TC (mmol/litre) } \\
\text { LDL (mmol/litre) } \\
\text { HDL (mmol/litre) } \\
\text { ApoA (g/litre) } \\
\text { ApoB (g/litre) } \\
\text { FFA (mmol/litre) } \\
\text { FL (g/litre) } \\
\text { ApoB/ApoA } \\
\text { TC/HDL } \\
\text { LDL/HDL } \\
\text { HDL/ApoA } \\
\text { FFA/TG }\end{array}$} & \multicolumn{2}{|c|}{ Pregnant women (38-42 weeks) } & \multicolumn{2}{|c|}{ Pregnant women (delivery) } & $\frac{\text { Newborn (umbilical vein) }}{0.39 \pm \text { SD } 0.18}$ \\
\hline & $\begin{array}{l}2.40 \pm \text { SD } 0.8 \\
6.49 \pm \text { SD } 1.10 \\
3.49 \pm \text { SD } 1.20 \\
1.76 \pm \text { SD } 0.41 \\
2.65 \pm \text { SD } 0.40 \\
1.35 \pm \text { SD } 0.33 \\
0.03 \pm \text { SD } 0.01 \\
2.88 \pm \text { SD } 0.43 \\
0.51 \pm S D 0.22 \\
3.68 \pm \text { SD } 0.9 \\
1.98 \pm \text { SD } 0.82 \\
0.66 \pm S D 0.05 \\
0.013 \pm S D 0.001\end{array}$ & $\begin{array}{l}\text { NS } \\
\text { NS } \\
\text { NS } \\
\text { NS } \\
\vdots \\
\text { NS } \\
\text { NS } \\
\dagger \\
\vdots \\
\text { NS } \\
\text { NS } \\
{ }^{*} \\
+\end{array}$ & $\begin{array}{l}1.95 \pm \text { SD } 1.31 \\
6.57 \pm \text { SD } 2.09 \\
3.57 \pm \text { SD } 1.60 \\
1.73 \pm \text { SD } 0.41 \\
2.29 \pm \text { SD } 0.55 \\
1.63 \pm \text { SD } 0.58 \\
0.04 \pm \text { SD } 0.02 \\
2.57 \pm \text { SD } 0.58 \\
0.71 \pm \text { SD } 0.27 \\
3.98 \pm \text { SD } 1.44 \\
2.19 \pm \text { SD } 1.07 \\
0.75 \pm \text { SD } 0.07 \\
0.02 \pm \text { SD } 0.002\end{array}$ & $\begin{array}{l}\ddagger \\
\ddagger \\
\ddagger \\
\ddagger \\
\ddagger \\
\ddagger \\
\ddagger \\
\text { NS } \\
\ddagger \\
\ddagger \\
\ddagger \\
\ddagger \\
\text { NS } \\
\text { NS }\end{array}$ & $\begin{array}{l}0.39 \pm \text { SD } 0.18 \\
1.63 \pm \text { SD } 0.54 \\
0.72 \pm \text { SD } 0.02 \\
0.80 \pm \text { SD } 0.25 \\
0.97 \pm \text { SD } 0.22 \\
0.38 \pm \text { SD } 0.04 \\
0.09 \pm \text { SD } 0.35 \\
1.27 \pm \text { SD } 0.67 \\
0.39 \pm \text { SD } 0.08 \\
2.05 \pm \text { SD } 0.47 \\
0.95 \pm \text { SD } 0.35 \\
0.81 \pm \text { SD } 0.06 \\
0.23 \pm S D 0.31\end{array}$ \\
\hline
\end{tabular}

Apo $\mathrm{A}=$ apolipoprotein $\mathrm{A} ; \mathrm{ApoB}=$ apolipoprotein $\mathrm{B} ; \mathrm{TC}=$ total cholesterol; $\mathrm{TG}=$ triglycerides; $\mathrm{HDL}=$ high density lipoprotein cholesterol; $\mathrm{LDL}=$ low density lipoprotein cholesterol; FFA = free fatty acid; $\mathrm{FL}=$ phospholipid.

cholesterol; $\mathrm{LDL}=0.05 ; \mathrm{p}<0.01 ; \neq \mathrm{p}<0.001$.

informed consent. All these samples were taken from an antecubital vein. Immediately after delivery and umbilical cord clamping a blood sample was taken from the umbilical vein. In all cases the following variables were determined: (1) by lipoprotein electrophoresis: total cholesterol, triglycerides, high density lipoproteins (HDL), low density lipoproteins (LDL); (2) by an enzymatic microtechnique $^{6-10}$ : free fatty acids (FFA) and phospholipids; (3) by simple radial immunodiffusion: apo-A and apo-B. Serum and plasma viscosities were measured with a Harkness capillary viscosimeter, series No 8052 (Coulter electronics). Statistical analysis consisted of Shapiro and Wilk's normality test, comparison of means test, Pearson's correlation study, and regression analysis.

\section{Results}

Mean values for lipids, proteins, and haemorheological variables in the pregnant women and in the neonates are given in tables 1 and 2 .
In pregnant women after 38 weeks of pregnancy most lipids did not change during delivery. Significant decreases, however, were observed in apo-A and phospholipid. The apo-B/apo-A and HDL/apo-A ratios increased during delivery, indicating that plasma in pregnant women is more atherogenic during delivery than at previous gestational stages. A change in the quantitative composition of HDL during delivery is indicated by an increase in the HDL apo-A ratio at this time. There were no significant differences between viscosities or serum protein fractions in pregnant women during delivery or at previous gestational stages.

Although there was a considerable difference between plasma lipid composition in the mother and neonate, there was no significant difference in their HDL/apo-A ratio. Also, in spite of the significantly lower triglyceride concentrations in the neonate compared to the mother, their FFA/triglyceride ratio is not significantly different.

Although serum and plasma viscosities were significantly different in mothers and neonates,

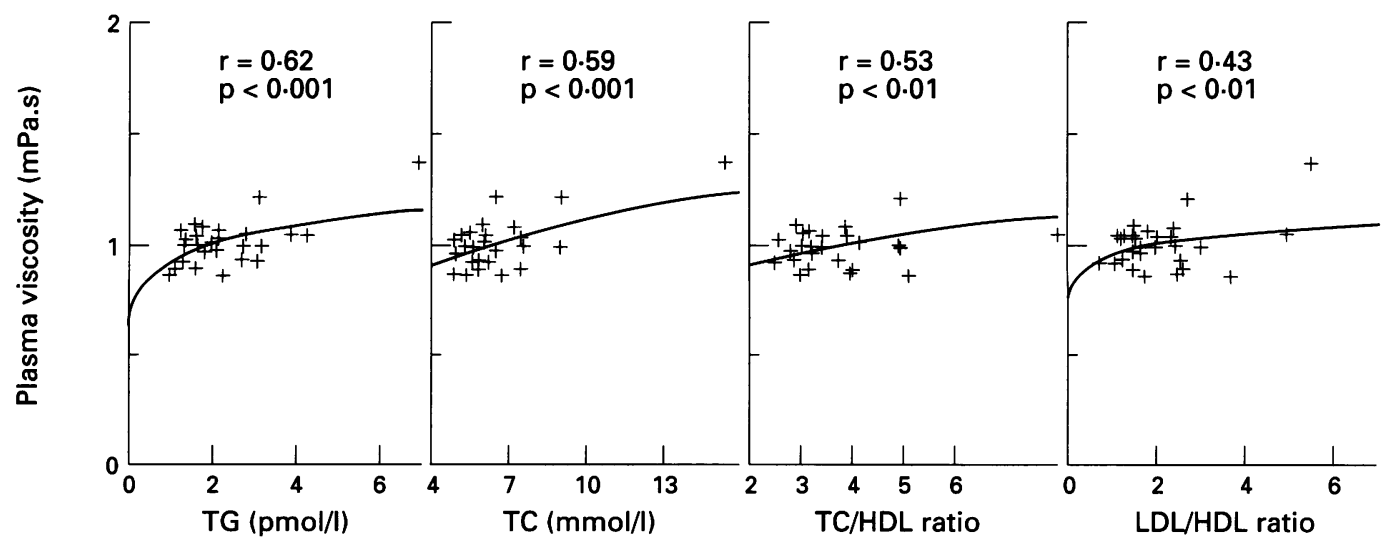

Correlation and regression analysis between plasma viscosity of the newborns with total cholesterol (TC), triglycerides (TG), TC/HDL, and $L D L / H D L$ ratios in pregnant women. 
the viscosity due to fibrinogen (plasma viscosity minus serum viscosity ${ }^{12}-0.06$ (SD $0.11) \mathrm{mPa} / \mathrm{s}$ for the pregnant mother and 0.04 $(0 \cdot 1) \mathrm{mPa} / \mathrm{s}$ for the neonate-was not statistically significantly different in the two groups.

The figure shows a significant correlation between maternal lipid variables (triglyceride, total cholesterol, LDL, total cholesterol/HDL, and LDL/HDL), and neonatal plasma viscosity. There did not, however, appear to be any significant relation between serum viscosity and maternal lipids. The difference between the plasma viscosity and the serum viscosity (viscosity due to fibrinogen) was correlated with the same lipid variables as the plasma viscosity. Other neonatal protein variables were significantly correlated with maternal triglyceride or total cholesterol: thus maternal triglyceride was correlated with albumin $(r=$ $0.37 ; \mathrm{p}<0.05)$ and neonatal $\alpha_{2}$ globulin $(r=$ $0.37 ; \mathrm{p}<0.05$ ), and maternal total cholesterol with albumin $(r=0.59 ; \mathrm{p}<0 \cdot 001)$ and neonatal $\alpha_{1}$ globulin $(r=0.36 ; \mathrm{p}<0.05)$.

\section{Discussion}

Lipid changes during pregnancy are a result of physiological adaptations to the state of pregnancy. ${ }^{13}$ As shown by our results, these short term changes persist until the moment of birth.

There is a significant decrease in apo-A levels during delivery compared with predelivery values. ${ }^{314}$ This decrease in apo-A is similar to that reported in other studies in pregnancies with intrauterine growth retardation. ${ }^{4}$ The significance of this is still unknown and should be the focus of future studies.

The apo-B/apo-A ratio, considered to be a reliable index of plasma atherogenicity, is significantly greater during delivery than at previous gestational stages, indicating that the lipoprotein profile becomes progressively more atherogenic up to the moment of birth. This has also been described by other investigators. ${ }^{35}$ Although FFA and triglyceride concentrations do not differ significantly before and those during delivery, on the basis of our findings the FFA/ triglyceride ratio is increased during delivery.

Maternal serum phospholipid concentrations are reduced at delivery (table 1). This could be the result of increased endothelial phospholipase $A_{2}$ activity and an increase in the synthesis of prostaglandins ${ }^{15}$ that accompany a normal birth.

An increase in fibrinogen synthesis in neonates with intrauterine growth retardation or suffering from stress before or after delivery is well documented. ${ }^{16-18}$ However, the relation between maternal lipid values and neonatal plasma rheology has not yet been reported. The correlation between lipid values during delivery and neonatal plasma viscosity, and the absence of a correlation with serum viscosity, indicates an increase in plasma atherogenicity in pregnant woman at term that could cause an increase in fibrinogen synthesis and plasma viscosity in the fetus. This is explained by the observation of similar relations between the difference in the two viscosities (the viscosity due to fibrinogen $)^{12}$ and maternal triglyceride, total cholesterol, LDL, total cholesterol/HDL, and LDL/HDL values. The viscosities observed in this study are equivalent to those reported in previous studies of pregnant women and neonates. ${ }^{19} 20$

In the absence of macroscopic placental lesions, as occurs in our group at delivery, the generation of placental lipid peroxides could be the cause of placental vasoconstriction ${ }^{21}$ and the fetal response of an increase in fibrinogen synthesis. ${ }^{162223}$ This would explain the relation between maternal lipids and fetal plasma viscosity, and the lack of correlation between fetal serum viscosity and the maternal lipid profile.

Although HDL and apo-A values are lower in the neonate, the HDL/apo-A ratio is not significantly different from the maternal value, apparently indicating that there is no difference between fetal and maternal HDL composition. On the other hand, the FFA/triglyceride ratios in neonates and their mothers at delivery are statistically similar (table 1) implying that endogenous triglyceride lipolysis in the fetus is not different from that observed in the pregnant woman during delivery (table 1). We can interpret the similar maternal and fetal FFA value and the significantly lower fetal triglyceride value as being due to the transplacental movement of FFA from the mother to the fetus.

In the light of these observations we conclude that plasma atherogenic indices during pregnancy progressively increase until the moment of birth and these changes have haemorheological consequences in the neonate, causing an increase in plasma viscosity.

This study was supported by the Neonatology Section of the Spanish Association of Paediatrics. We wish to thank Ms Ana Gómez-Vélez and Ms Caroline Hoope for translating the original manuscript into English.

1 Potter JM, Nestel PJ. The hyperlipidemia of pregnancy in normal and complicated pregnancies. Am $\mathcal{f}$ Obstet Gynecol 1979;133:165-70.

2 Darmday JM, Postle AD. Lipid metabolism in pregnancy. Br F Obstet Gynaecol 1982;89:211-5.

3 Jimenez DM, Pocovi M, Ramon-Cajal J. Longitudal study of plasma lipids and lipoprotein cholesterol in normal pregnancy and puerperium. Gynecol Obstet Invest 1988; 25:158-64.

4 Muñoz A, Uberos J, Molina A, Valenzuela A, Cano D, Ruiz C, et al. Relation of blood rheology to lipoproteic profile during normal pregnancies and those with intrauterine growth retardation. $\mathcal{f}$ Clin Pathol 1994;48:571-4.

5 Piechota W, Staszewski A. Reference ranges of lipids and apolipoproteins in pregnancy. Eur $\mathcal{F}$ Obstet Gynecol Reprod Biol 1992;45:27-35.

6 Allain CL, Poon CJ, Chan CSG, Richmond WW, Fu PL. Enzymatic determination of total serum cholesterol. Clin Chem 1974;20:470-6.

7 Lopes-Virella MF, Stone PG, Ellis S, Colwell JA. Cholesterol determination in high density lipoproteins separated by three different methods. Clin Chem 1977;23:882-6.

8 Hoppe F. Eine neve einfeche Methode zuz bertin mung der Triglyceride. MTA Zeitschrift 1980;7:293-8.

9 Takayama MN, Itoh S, Nagasaki T, Tinimizu I. A new enzymatic method for determination of serum choline containing phospholipids. Clin Chim Acta 1977;79:93-8

10 Friedwald WT, Levy RI, Frederickson DS. Estimation of plasma low dity lion plasma low density lipoprotein cholesterol concentration without use of the pre

11 Hudson L, Fay FC. Interacción del anticuerpo con el antígeno. In: Hudson L, Fay FC, eds. Inmunología práctica.

12 Ernst E, Resch KL, Saradeth T, Maier A, Matrai A. A viscosimetric method of measuring plasma fibrinogen concentrations. f Clin Pathol 1992;45:534-5.

13 Piccaro M, Rastelli D, Lombardo F, Ferrazzani S, Bondoli A, Cagnetta G, et al. Fisiopatologia in gravidanza: quadro reologico e bioumorale nella gravidanza normale e patologica. Minerva Ginecol 1982;34(4):111-26.

14 Fahreus L, Larsson-Cohn U, Wallentin L. Plasma lipoproteins including high density lipoprotein subfractions during normal pregnancy. Obstet Gynecol 1985;66:468-72. 15 Yedgar S, Vlodavsjy I, Panet A, Reisfeld N, Eldor A. In- 
terferon enhances phospholipase A2 activity in bovine aortic endothelial cells. Eicosanoids 1990;3:225-9.

16 Pickart LR, Creasy RK, Thaler MM. Hyperfibrinogenemia and polycythemia with intrauterine growth retardation in fetal lambs. Am $\mathcal{F}$ Obstet Gynecol 1976;124:268-71.

17 Black V. Neonatal hyperviscosity syndromes. Curr Probl Pediatr 1987;17:73-130.

18 Thorburn J, Drummond MM, Whigham KA, Lowe GDO Forbes $C D$, Prentice CRM, et al. Blood viscosity and Forbes CD, Prentice haemostatic factors in late pregnancy, pre-eclampsia and fetal growth retardation. $\mathrm{Br} \mathcal{F}$ Obstet Gynaecol 1982;89: 19 Muñoz

Muñoz A, Uberos J, Bonillo A, Valenzuela A, Puertas A,
Narbona E, et al.. Plasma and internal erythrocyte viscosity in umbilical artery and vein of premature infants with and without acute asphyxia. Clin Hemorheol 1994;14:75-82.
20 Uberos J, Muñoz A, Puertas A, Valenzuela A, Molina A Rodriguez MT. Análisis comparativo de la viscosidad plasmática durante la gestación y periodos feto-neonatal. Contribución de las fracciones proteicas. An Esp Pediatr 1994;41:187-9.

21 Walsh SW, Wang Y. Secretion of lipid peroxides by the human placenta. Am f Obstet Gynecol 1993;169:1462-6.

22 Walker AM. Circulatory transitions at birth and the control of the neonatal circulation. In: Hanson MA, Spencer JD, Rodeck CH. Fetus and neonate. Physiology and clinical applications. Cambridge: Cambridge University Press, 1993:160-96.

23 Stegnar M, Zore A, Novak-Antolic Z, Vovk N, Kruithof EKO. Tissue-type plasminogen activator after venous occlusion in pregnancy and puerperium. Thromb Haemost 1993;70:486-90. 